\title{
COMPARISON BETWEEN LOCAL APPLICATION OF DOXYCYCLINE LOADED NANOPARTICLES AND CONVENTIONAL DOXYCYCLINE GEL ON MATRIX METALLOPROTEINASE 1 AND BONE DENSITY IN CHRONIC PERIODONTITIS
}

\author{
Enas Ahmed Elgendy*
}

\begin{abstract}
Background \& Objective: Nanoparticles have received considerable attention in recent years. This study was conducted to compare between doxycycline loaded nanoparticles (DLNs) and conventional doxycycline gel (CDG) in management of chronic periodontitis (CP).
\end{abstract}

Materials and Methods: This randomized, split mouth study was conducted on 40 sites among 20 patients with chronic periodontitis. The sites were randomly allocated into a control group, receiving scaling and root planing (SRP) plus CDG, and an experimental group, receiving SRP plus DLNs. Clinical parameters and levels of matrix metalloproteinase 1 (MMP1) were assessed at baseline, 1,3 and 6 months post treatment. Bone density was also assessed at baseline and 6 months after treatment.

Results: The results, following the use of both treatment gel formulas, showed a statistically significant reduction in all tested clinical parameters and levels of MMP1 at 1,3 and 6 months post treatment along with significant increase in bone density after 6 months. However, DLNs treatment achieved a significant reduction not only in clinical parameters but also in MMP1 as compared to CDG treated group. In addition, The DLNs showed a significant bone formation as compared to CDG group.

Conclusion: DLNs shows promise as adjunctive local therapy for management of patients with chronic periodontitis.

Clinical Relevance: Scientific Rationale for Study: Evaluating the effect of doxycycline loaded nanoparticles gel and conventional doxycycline gel on treatment of chronic periodontitis. Principal Findings: Findings from this randomized, split mouth study of 40 sites among 20 patients with chronic periodontitis supported the potential of doxycycline loaded nanoparticles and conventional doxycycline gel for providing an effective therapy for chronic periodontitis, along with improving clinical parameter, bone density and decreasing matrix metalloproteinase 1. Practical Implications: Doxycycline loaded nanoparticles are proved to be more effective than conventional doxycycline gel as an adjunctive treatment of chronic periodontitis.

Keywords: Chronic periodontitis, Conventional doxycycline gel, Doxycycline loaded nanoparticles, Matrix metalloproteinase 1, Bone density.

* Assistant Prof. of Oral medicine, Periodontology, Oral Diagnosis and Radiology Department, Faculty of Dentistry, Delta University 


\section{INTRODUCTION}

Chronic periodontitis is defined as inflammation of the gingiva extending into the adjacent attachment apparatus. This disease is characterized by the loss of clinical attachment due to destruction of the periodontal ligament and loss of the adjacent supporting bone ${ }^{[1]}$. The organisms that cause this disease reside in unique structures, termed biofilms that offer partial protection to the colonizing organisms from the defence mechanisms of the host as well as from the antimicrobials used for the treatment ${ }^{[2]}$.

Matrix Metalloproteinases (MMPs) are family of neutral proteases that are released from different cell types including macrophages, leucocytes, fibroblasts and other resident cells ${ }^{[3]}$. MMP-1, prototype interstitial collagenase, is the first vertebrate collagenase, ${ }^{[4]}$ which is widely distributed in tissues and expressed by fibroblasts, keratinocytes, endothelial cells, osteoblasts, chondrocytes, and monocytes/macrophages ${ }^{[5,6]}$. Many studies showed increased expression of MMP-1 mRNA in inflamed gingival tissue of patients with chronic periodontitis as compared to healthy controls ${ }^{[6,7-10]}$.

Mechanical debridement has been the most widely used approach to treat periodontal diseases. However, mechanical debridement alone cannot effectively eliminate most of the causative bacteria, and it is usually associated with high recurrence rate ${ }^{[11]}$. As a result, locally delivered, anti-infective pharmacological agents have been employed in attempts to treat local bacterial infections associated with periodontitis. For example, chlorhexidine, tetracycline, minocycline, metronidazole, doxycycline, as well as other antimicrobials and antiseptics have been used as adjunctive to scaling and root planing to reduce periodontal inflammation ${ }^{[12]}$.

Doxycycline is a potentially valuable antibiotic with a broad spectrum activity against numerous periodontal pathogens which has the ability to concentrate in the gingival crevicular fluid greater than in the serum ${ }^{[13]}$. Moreover, it demonstrates anti-collagenolytic and antiproteolytic properties that do not only aid osseous regeneration but also help in reducing periodontal disease progression ${ }^{[14]}$.

Biodegradable nano/microparticles of poly D, L-lactide-co-glycolide (PLGA) and PLGAbased polymers are widely explored as carriers for controlled delivery of macromolecular therapeutics such as proteins, peptides, vaccines, genes, antigens, growth factors ${ }^{[15]}$. Moreover,PLGAallows sustained drug release within the target site over a period of days to weeks and thus increasing the therapeutic benefit while minimizing side effects ${ }^{[16]}$.

Indeed, the purpose of this study was to compare between doxycycline loaded nanoparticles (DLNs) and conventional doxycycline gel (CDG) on Matrix metalloproteinase 1 (MMP1) and bone density in chronic periodontitis $(\mathrm{CP})$.

\section{MATERIAL AND METHODS}

\section{Patients' selection:}

Randomized, split mouth study was carried out in the Department of Oral Medicine, Faculty of Dentistry, Delta University from June 2016 to May 2017. This study was conducted on 20 patients, 8 males and 12 females, in a good physical health with no evidence of any relevant systemic diseases. This study was approved by the Research Ethical Committee of Delta University and written informed consent was obtained from each patients. All the patients were suffering from severe chronic periodontitis determined by both clinical and radiographic examinations. A total of 40 sites among the participants were selected for the study. This study complied with the Helsinki Declaration of 1964, as revised in 2004. There were no conflicts of interest in this study. Each of the enrolled patients had at least two sites one in each quadrant with probing depth of $\geq 5 \mathrm{~mm}$. 


\section{Exclusion criteria:}

Exclusion criteria for this study included:

- People who suffer from any systemic disease that affect the periodontium.

- Pregnant, postmenopausal women.

- People who take anti-inflammatory drugs, antibiotics or vitamins within the previous 3 month.

- People who use mouth washes regularly

- Smokers

- Alcoholic abusers

- Participants in other clinical trials.

\section{Materials:}

Preparation of Doxycycline gel (10\%) gel

Doxycycline gel $(10 \%)$ was prepared in the Faculty of Pharmacy, Delta University, Egypt, according to the method reported by Vandana et al., ${ }^{[17]}$

\section{Ingredients}

Doxycycline hyclate $25 \mathrm{mg}$ (Sigma, Egypt), propylene glycol $0.25 \mathrm{~g}$, poly lactide-co-glycolide ( PLGA) $0.50 \mathrm{~g}$, triacetin $4.25 \mathrm{~g}$.

\section{Procedure:}

PLGA was placed in a glass vial, and then triacetin was added, heated at $60^{\circ} \mathrm{C}$, and agitated using a mechanical shaker overnight in order to obtain a clear solution. Doxycycline, dissolved in propylene glycol, was then added to the polymer solution and sonicated for 30 seconds to get a uniform dispersion.

\section{Preparation of (10\%) doxycycline nanoparticles gel}

The encapsulation of the drug into a biodegradable polymer PLGA was done by the nanotech company for photo- electronics (Dreamland, El Wahat road, 6 October City).

\section{Procedure}

Oil in water $(\mathrm{O} / \mathrm{W})$ emulsion technique was used to prepare doxycycline loaded PLGA nanoparticles. The steps are as follows. First, the oil phase was created by dissolving PLGA in acetone at room temperature and doxycycline was added to poly vinyl alcohol $(30 \mathrm{kDa})$ solution to prepare the water phase. The oil phase was pipetted into the water phase slowly and homogenized (Ultra-turrax, IKA, Germany) at $8000 \mathrm{rpm}$ for 5 minutes. Finally, after evaporation, nanoparticles were collected by centrifugation and washed three times to remove nonencapsulated drug. Finally, a gelatinous solution was obtained.

\section{Patient groups:}

The selected qualifying sites (the most periodontally affected site in each quadrant) were randomly divided into one of the parallel treatment arms according to split mouth design into two groups:

Group I (Control group): it included 20 sites which received oral hygiene instructions and SRP (with hand instruments) of all teeth plus $10 \%$ conventional doxycycline gel (CDG). The process was repeated at 7 and 14 day to maintain effective levels for periodontopathogens microorganisms.

Group II (Experimental group): it included 20 sites, which received oral hygiene instructions and SRP (with hand instruments) of all teeth, followed by placement of $10 \%$ doxycycline loaded nanoparticles (DLNs). The process was repeated at 7 and 14 day.

The gel was administered by means of a syringe with a bent, blunt-end needle. After drying of the site, the needle was carefully inserted into the periodontal pocket, and the gel was applied in the test sites, attempting to fill the full extent of the pocket. Gel was applied up to the gingival margin (Figure 1), and the excess of gel was removed with sterile gauze. 


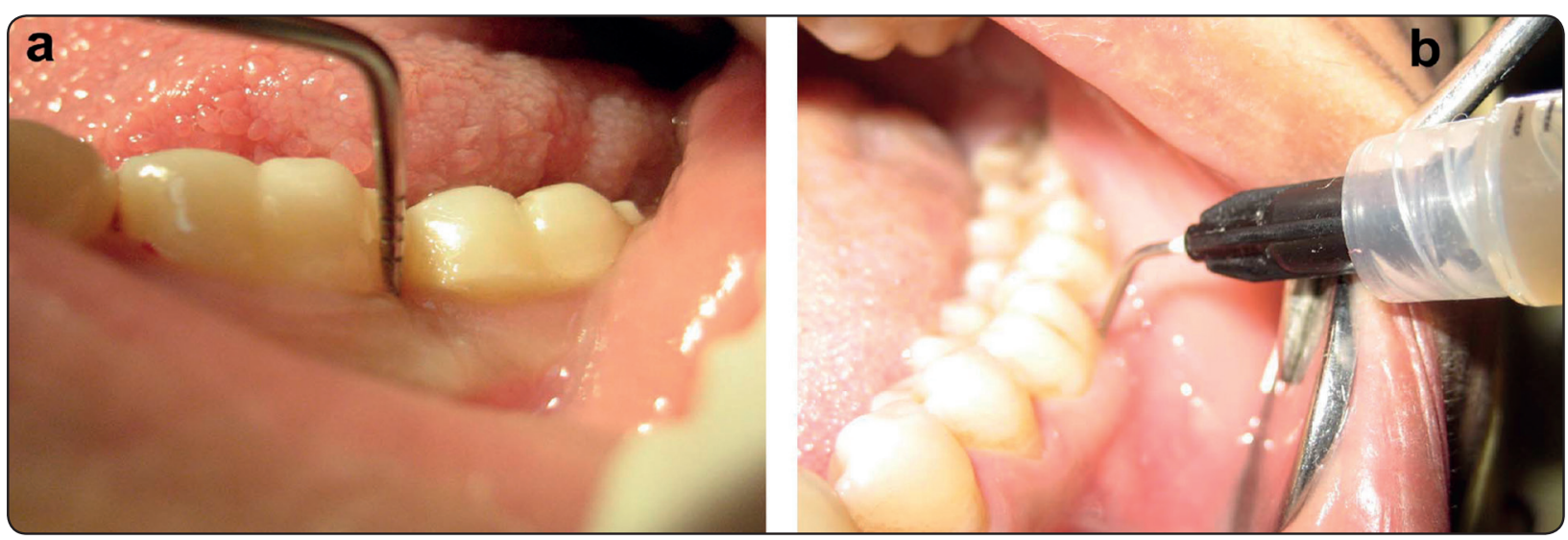

Fig. (1) a) Base-line PPD measurement b) Subgingival application of $10 \%$ doxycycline loaded nanoparticles (DLNs). into the periodontal pocket, after SRP.

Patients were instructed to avoid dental floss at the sites of gel inserts for 10 days after placement, because flossing might dislodge the gel. All other oral hygiene may be continued as usual. No restrictions regarding dietary habits were needed. Patients should notify promptly if pain, swelling or other problems occur.

\section{Clinical measurements:}

The periodontal status of the women was determined by recording:

1. Plaque Index (PI) according to Sillness \& Loe, ${ }^{[18]}$.

2. Gingival index (GI) according to Loe \& Silness ${ }^{[19]}$.

3. Probing pocket depth (PPD) according to Ramfjord ${ }^{[20]}$.

4. Clinical attachment level (CAL) according to Ramfjord ${ }^{[20]}$.

All clinical parameters were recorded at baseline, 1, 3 and 6 months post treatment. The maintenance was also applied during these visits.

Collection of Gingival crevicular fluid (GCF) samples:

Samples were collected in the mid-morning hours, ${ }^{[21]}$ from the most periodontally affected sites
(PPD $\geq 5 \mathrm{~mm}$ ) in patients with chronic periodontitis at baseline, 1, 3 and 6 months after treatment. Gingival crevicular fluid was collected by the method used by Wilson et al., ${ }^{[22]}$ after isolation and drying of the test site, pre-sterilized filter paper strips were inserted at the entrance of the test pocket for $30 \mathrm{sec}$. after that, the strip was placed in a sterile microcentrifuge vial with $1 \mathrm{ml}$ Tris-HCL $(\mathrm{pH}=6.5)$ and then stored at $-70 \mathrm{C}^{\circ}$. GCF levels of MMP-1 was analysed using ELISA, performed by using a commercial ELISA kit (RayBio-Human MMP-1 ELISA Kit protocol (Cat: ELH-MMP1-001).

\section{Radiographic Examination}

Digital panorama radiographs were obtained from each patient before treatment and at 6 months after treatment. All radiographs were obtained by the same X-ray machine (Planmeca, Asentajankatu 6 FIN-00880 Helsinki, Finland).

The region of interest (ROI) was determined in each radiograph as the region which begins $1 \mathrm{~mm}$ below the cement-enamel junction and down toward the root apex $7 \mathrm{~mm}$ in length. The gray levels were carried out using Digora software (Digora system, Soredex, Orion Corp., Finland). The program measured the optical density of each picture element (pixel; gray level), quantified them all and gave a numerical measurement. 


\section{Statistical analysis:}

All the results were tabulated and statistically analyzed using computer software named the Statistical Package for Social Science (SPSS version 16). Comparison between the studied groups was performed with independent samples student $\mathrm{t}$-test and comparison within the studied groups was performed with paired t-test at a level of $5 \%$ significance.

\section{RESULTS}

\section{Patients}

The participant's age ranged between 35 and 50 years with a mean $41.50 \pm 4.23$. At baseline, the two treatment groups showed no significant differences regarding the tested parameters [plaque index (PI), gingival index (GI), probing pocket depth (PPD), clinical attachment level (CAL), bone density
(BD), matrix metalloproteinase 1(MMP1)]. This was evidenced by their baseline values $(\mathrm{P}>0.05)$ (tables 1\& 2).

\section{Clinical results}

Firstly, in group 1, results showed that there was a significant reduction of the mean PI and GI which continued up to the end of the 6 month evaluation period as compared to the mean baseline value $(2.47 \pm 0.47,2.61 \pm 0.45$ respectively). Secondly, results of group II, showed a reduction in the mean PI and GI which continued up to the end of 6 months as compared to the mean baseline value $(2.28 \pm 0.45$, $2.46 \pm 0.45$ respectively), and this reduction was statistically significant as compared to baseline value $(\mathrm{P}<0.001)$. Furthermore, intergroup comparison of the results using t-test at all evaluation periods showed statistically insignificant difference between the two treated groups.

TABLE (1) Mean values of plaque index (PI), gingival index (GI) and probing pocket depth (PPD) among the study groups at baseline, 1, 3 and 6 months after treatment.

\begin{tabular}{|c|c|c|c|c|}
\hline Parameters & Time of assessment & $\begin{array}{c}\text { Group } I=n=20 \\
\text { mean } \pm \text { SD }\end{array}$ & $\begin{array}{c}\text { Group } \mathrm{II}=\mathbf{n}=\mathbf{2 0} \\
\text { mean } \pm \text { SD }\end{array}$ & P-values \\
\hline \multirow{5}{*}{ Plaque Index } & Base-line & $2.47 \pm 0.47$ & $2.28 \pm 0.45$ & 0.230 \\
\hline & 1 month & $0.53 \pm 0.33$ & $0.47 \pm 0.27$ & 0.513 \\
\hline & 3 months & $0.47 \pm 0.29$ & $0.40 \pm 0.20$ & 0.436 \\
\hline & 6 months & $0.48 \pm 0.29$ & $0.44 \pm 0.24$ & 0.655 \\
\hline & & $\mathrm{P} \leq 0.001$ & $\mathrm{P} \leq 0.001$ & \\
\hline \multirow{5}{*}{ Gingival Index } & Base-line & $2.61 \pm 0.45$ & $2.46 \pm 0.45$ & 0.292 \\
\hline & 1 month & $0.43 \pm 0.33$ & $0.37 \pm 0.29$ & 0.521 \\
\hline & 3 months & $0.42 \pm 0.23$ & $0.32 \pm 0.23$ & 0.238 \\
\hline & 6 months & $0.40 \pm 0.25$ & $0.39 \pm 0.24$ & 0.870 \\
\hline & & $\mathrm{P} \leq 0.001$ & $\mathrm{P} \leq 0.001$ & \\
\hline \multirow{5}{*}{ Probing Pocket Depth } & Base-line & $6.21 \pm 0.91$ & $6.52 \pm 0.61$ & 0.220 \\
\hline & 1 month & $4.47 \pm 0.69$ & $3.78 \pm 0.71$ & $0.005^{*}$ \\
\hline & 3 months & $4.26 \pm 0.65$ & $3.73 \pm 0.45$ & $0.007 *$ \\
\hline & 6 months & $4.05 \pm 0.77$ & $3.52 \pm 0.51$ & $0.019 *$ \\
\hline & & $\mathrm{P} \leq 0.001$ & $\mathrm{P} \leq 0.001$ & \\
\hline
\end{tabular}


Table $(1,2)$ demonstrates a statistically significant reduction in the mean PPD and CAL up to 6 months as compared to the mean baseline value $(6.21 \pm 0.91$, $5.36 \pm 0.49$ respectively) in group I. Results of sites treated with doxycycline loaded nanoparticles revealed that the mean PPD and CAL was reduced at all evaluation periods and this reduction was statistically significant as compared to baseline value $(\mathrm{P}<0.001)$. At all evaluation periods, $\mathrm{t}$-test showed a significant difference between the two treated groups at any time of the evaluation period.

\section{Bone density results}

Results of sites treated with $10 \%$ conventional doxycycline gel showed a statistically significant rise in the mean values of $\mathrm{BD}$ after six month followup compared with baseline values (74.30 \pm 8.31 , $95.75 \pm 9.48$ respectively) $(\mathrm{P}<0.001)$ (Figure 2$)$. In group II, Table (2) demonstrated a statistically significant increase in the mean $\mathrm{BD}$ at 6 month evaluation period as compared to the mean baseline value (72.44 \pm 7.83 ) (Figure 3).
Moreover, comparison between the two treatment modalities showed no statistically significant difference in the mean BD baseline values meanwhile, at 6 months the sites treated with $10 \%$ doxycycline loaded nanoparticles (DLNs) resulted in more rise in $\mathrm{BD}$ values which was statistically significant compared to sites treated with $10 \%$ conventional doxycycline gel $(P<0.001$; Table 2$)$.

\section{Matrix metalloproteinase 1 results:}

Results of group I revealed that mean MMP1 was reduced from $23.25 \pm 2.33$ to $8.80 \pm 1.00,9.55 \pm 1.09$, $10.15 \pm 1.46$ at 1,3 and 6 months respectively, and this reduction was statistically significant as compared to baseline value $(\mathrm{P}<0.001)$. Results of sites treated with 10\% doxycycline loaded nanoparticles (DLNs) revealed that the mean MMP1 was reduced from $22.90 \pm 2.07$ to $7.90 \pm 1.02,8.35 \pm 0.98$, and $8.75 \pm 1.25$ at 1,3 , and 6 months respectively. This reduction was also statistically significant as compared to baseline value $(\mathrm{P}<0.001)$. With intergroup comparing, the

TABLE (2) Mean values of clinical attachment level (CAL), bone density (BD) and MMP-1(ng/ml) among the study groups at baseline, 1, 3 and 6 months after treatment.

\begin{tabular}{|c|c|c|c|c|}
\hline Parameters & Time of assessment & $\begin{array}{c}\text { Group I= n= 20 } \\
\text { mean } \pm \text { SD }\end{array}$ & $\begin{array}{c}\text { Group II= n=20 } \\
\text { mean } \pm \text { SD }\end{array}$ & P-values \\
\hline \multirow{4}{*}{$\begin{array}{c}\text { Clinical Attachment } \\
\text { level }\end{array}$} & Base-line & $5.36 \pm 0.49$ & $5.84 \pm 0.60$ & 0.247 \\
\cline { 2 - 5 } & 1 month & $3.94 \pm 0.77$ & $3.47 \pm 0.51$ & $0.033^{*}$ \\
\cline { 2 - 5 } & 3 months & $3.89 \pm 0.45$ & $3.21 \pm 0.41$ & $0.000^{*}$ \\
\cline { 2 - 5 } & 6 months & $3.73 \pm 0.45$ & $3.26 \pm 0.45$ & $0.003^{*}$ \\
\hline \multirow{3}{*}{ Bone Density } & Base-line & $\mathrm{P} \leq 0.001$ & $\mathrm{P} \leq 0.001$ & \\
\cline { 2 - 5 } & 6 months & $94.30 \pm 8.31$ & $72.44 \pm 7.83$ & 0.472 \\
\cline { 2 - 5 } & & $\mathrm{P} \leq 0.001$ & $110.68 \pm 12.18$ & $0.000^{*}$ \\
\hline \multirow{3}{*}{$\begin{array}{c}\text { Matrix } \\
\text { metalloproteinase 1 }\end{array}$} & Base-line & $23.25 \pm 2.33$ & $22.90 \pm 2.07$ & 0.619 \\
\cline { 2 - 5 } & 1 month & $8.80 \pm 1.00$ & $7.90 \pm 1.02$ & $0.008^{*}$ \\
\cline { 2 - 5 } & 3 months & $9.55 \pm 1.09$ & $8.35 \pm 0.98$ & $0.001^{*}$ \\
\cline { 2 - 5 } & 6 months & $10.15 \pm 1.46$ & $8.75 \pm 1.25$ & $0.002^{*}$ \\
\hline
\end{tabular}




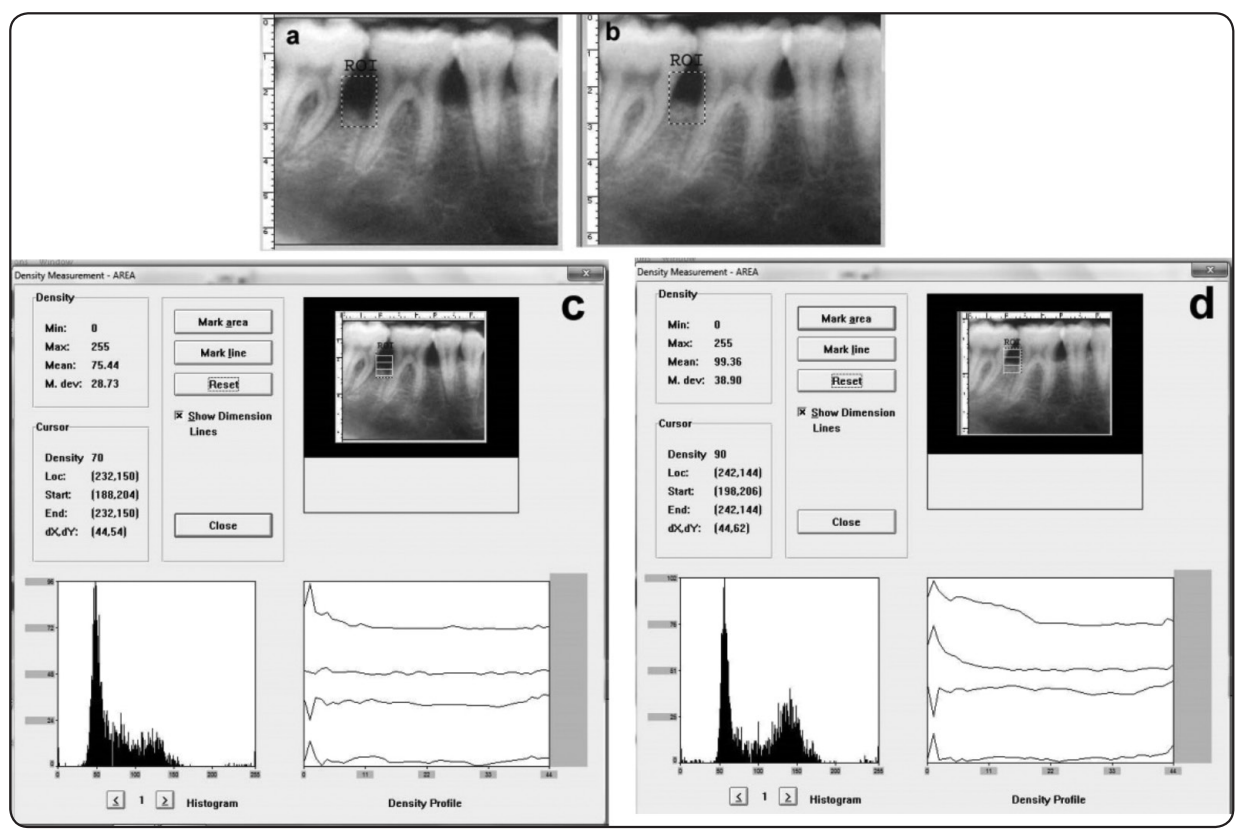

Fig. (2) a, b) Photograph showing the gray level of bone at baseline $(\mathrm{a}, \mathrm{c})$ and after 6 months post treatment $(b, d)$ in group I.

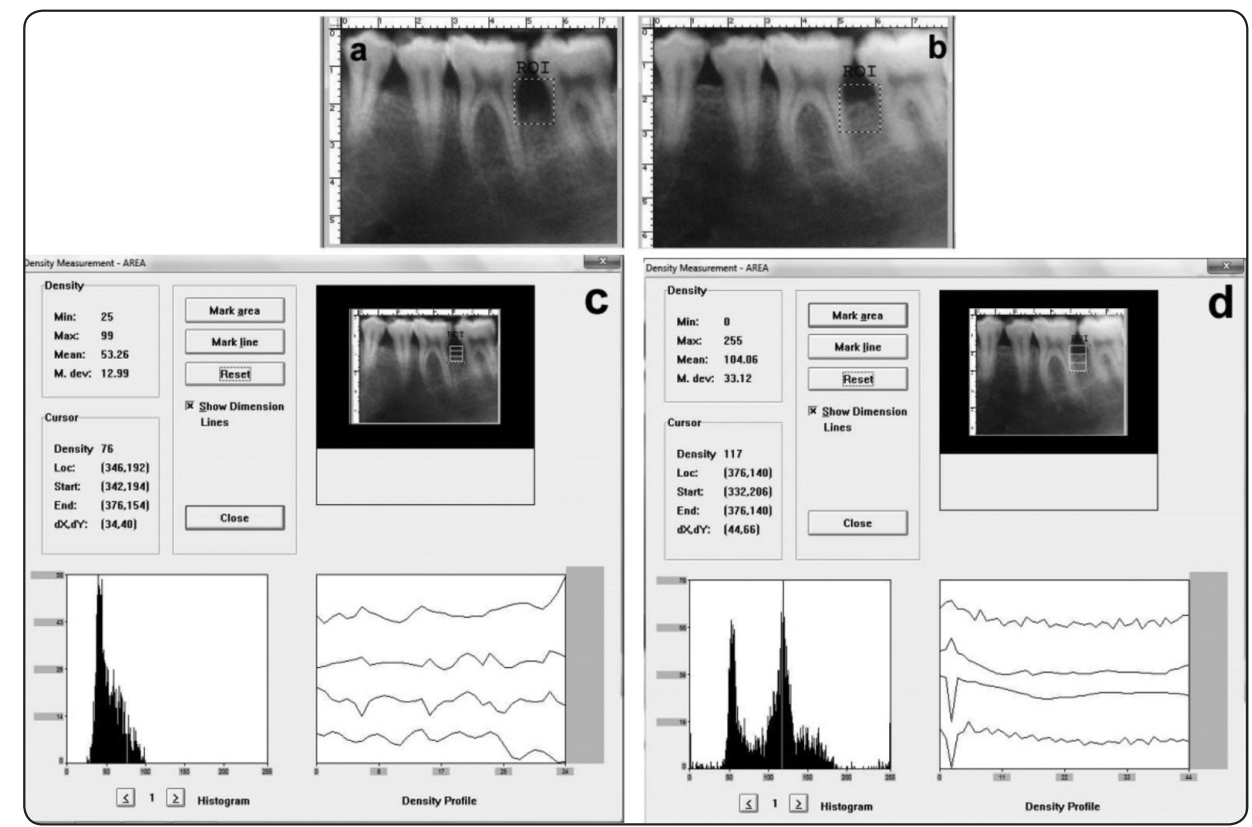

Fig. (3) a, b) Photograph showing the gray level of bone at baseline $(\mathrm{a}, \mathrm{c})$ and after 6 months post treatment $(b, d)$ in group II.

data shows that the mean difference of MMP1 at baseline was statistically insignificant between all treated groups. At all evaluation periods, there was a statistically significant reduction in the mean difference of MMP1 in group II (10\% doxycycline loaded nanoparticles (DLNs)) as compared to group I $(10 \%$ conventional doxycycline gel $)(\mathrm{P}<0.01)$.

\section{DISCUSSION}

Chronic periodontitis has a multifactorial aetiology with dental plaque as the initiating factor which its progression is related to the colonization of microorganisms ${ }^{[23]}$. Locally delivered antimicrobial agents are usually preferred as this mode of administration usually increases the concentration of the drug at the site of action concomitantly with low- 
ered total dose of drug thereby reducing the risk of systemic side effects ${ }^{[24]}$. Many of well controlled trials, that evaluated the efficacy of various locally delivered antimicrobial agents, have demonstrated better clinical response with doxycycline, when used as an adjunct to scaling and root planing (SRP) [25-27]. Polymers like polylactides (PLA), polyglycolides (PGA), poly lactide-co-glycolides (PLGA), are approved by the World Health Organization (WHO) and Food and Drug Administration (FDA) as materials that can be used in medicine and pharmacy ${ }^{[28]}$. Moura et al., demonstrated a successful sustained release of locally delivered doxycycline by poly lactide-co-glycolide (PLGA) microspheres in the periodontal pocket of patients with chronic periodontitis treated by non-surgical periodontal therapy ${ }^{[29]}$.

This study was designed as a split-mouth investigation to facilitate the comparison of two treatment procedures by eliminating patient-specific characteristics that might have an impact on the results of regenerative surgeries ${ }^{[30,31]}$. The split-mouth design had been considered adequate for evaluating regenerative procedures in a recent systematic review ${ }^{[32]}$. Wenzel et al., ${ }^{[33]}$ reported that no increased bone fill was illustrated between 6 and 12 months which may support why the 6-month radiographic analysis was preferred in the present study.

In the present study, the results showed no significant differences regarding the PI and GI at baseline and at all evaluation periods between the tested groups. Results of the present study showed that there was a reduction in the mean PI and GI scores during the study periods in all groups as compared to baseline values. At all evaluation periods, the reduction of PI in both groups may be attributed to adequate maintenance of oral hygiene, which was instructed to each patient, and anti-bacterial properties of doxycycline. The reduction of GI in both group may be attributed to anti-inflammatory properties of doxycycline which include down regulation of the expression of pro-inflammatory mediators and cytokines, and suppression of polymornuclear leukocytes activity along with the scavenging action on reactive oxygen metabolites ${ }^{[34,35]}$.

Results of PPD and CAL revealed that there was a reduction at 1,3 and 6 months evaluation period at both group as compared to the mean baseline value. The improvement of CAL and PPD in group I was demonstrated by Garrett et al., ${ }^{[36]}$. Polson et al., ${ }^{[37]}$. Wennstrom et al., ${ }^{[38]}$ who examined the ability of doxycycline gel to improve PPD and CAL in chronic periodontitis. Furthermore, Choi et al., ${ }^{[39]}$ found that tetracycline inhibit the degradation of extracellular matrix due to its ability to inhibit MMPs activity which is a result of depriving them of divalent cations, their activity's co-factors.

Moreover, comparison between the two treatment modalities showed statistically significant difference in the mean PPD and CAL values at all evaluation Periods. In addition, comparison between the two treatment modalities showed statistically significant difference in the mean $\mathrm{BD}$ values at 6 months in tested group $(P<0.001)$. This improvement in group II may be attributed to the enhanced properties of nanostructured doxacycline gel including its stability, high penetration of areas, physical bonding with tissues and improved drug performance ${ }^{[40]}$. On the other side, conventional drug content tends to be released rapidly after the administration, which may cause a rapid increase of the drug concentration in the body. Concentration oscillations of the administered drug may cause alternating periods of ineffectiveness and toxicity ${ }^{[41]}$.

Periodontal destruction is most likely caused by MMPs derived by the host cell. It has been suggested that MMP-1 may play an important role in the initiation of collagen degradation in periodontal disease $^{[6]}$. In both groups, the results revealed that there was statistically significant reduction in the mean of MMP1 as compared to baseline value $(\mathrm{P}<0.001)$. At all evaluation periods there was 
a statistically significant reduction in the mean difference of MMP1 in group II (10\% doxycycline loaded nanoparticles as compared to group I (10\% conventional doxycycline gel) $(\mathrm{P}<0.01)$. These findings are in accordance with Tuter et al., ${ }^{[42]}$ and Popat et al., ${ }^{[43]}$ who found that GCF levels of MMP-1 were significantly reduced in subjects with chronic periodontitis after 1 month from scaling and root planning as compared to baseline. In contrast, Birdt et al., ${ }^{[4]}$ stated that there was no significant difference in GCF levels of MMP-1in diseased and healthy sites. This variation in finding can be due to difference in methodology of both studies. In present study, we used ELISA to determine GCF levels of MMP-1 and the reduction in MMP-1 in both groups can be also explained by anticollagenase activity of doxycycline ${ }^{[34,44]}$.

\section{CONCLUSION}

Based on these findings, it can be claimed that both doxycycline loaded nanoparticles and conventional doxycycline gel were effective in the treatment of chronic periodontitis. Accordingly, superior clinical, biochemical and radiological outcomes make doxycycline loaded nanoparticles more effective in the treatment of chronic periodontitis.

\section{RECOMMENDATION}

Results of the present investigation create a new avenue for further studies on the effect of the doxycycline loaded nanoparticles in the treatment of aggressive periodontitis, furcation defects and other intrabony defects.

\section{REFERENCES}

1- The American Academy of Periodontology. Parameter on Chronic Periodontitis with Slight to Moderate Loss of Periodontal Support. J Periodontol. 2000;71:853-855.

2- Haffajee AD, Socransky SS, Gunsolley JC. Systemic antiinfective periodontal therapy. A systematic review. Ann Periodontol. 2003;8:115-81.
3- Preshaw PM, Taylor JJ. Periodontal pathogenesis, in: Newman MG, Takei H, Klokkevold PR, Carranza FM (Eds.), Carranza's Clinical Periodontology, 11th ed., Saunders publication, 2012, pp. 285-293.

4- Goldberg GI, Wilhelm SM, Kronberger A, Bauer EA, Grant GA, Eisen AZ. Human fibroblast collagenase. Complete primary structure and homology to an oncogene transformation-induced rat protein. J Biol Chem. 1986;15;261:6600-5.

5- Westerlund U, Ingman T, Lukinmaa PL, Salo T, Kjeldsen L, Borregaard N, et al. Human neutrophil gelatinase and associated lipocalin in adult and localized juvenile periodontitis. J Dent Res. 1996;75:1553-63.

6- Aiba T, Akeno N, Kawane T, Okamoto H, Horiuchi N. Matrix metalloproteinases- 1 and -8 and TIMP-1 mRNA levels in normal and diseased human gingivae. Eur J Oral Sci. 1996;104:562-9.

7- Nomura T, Takahashi T, Hara K. Expression of TIMP-1, TIMP-2 and collagenase mRNA in periodontitis-affected human gingival tissue. J Periodontal Res. 1993;28:354-62.

8- Kubota T, Nomura T, Takahashi T, Hara K. Expression of mRNA for matrix metalloproteinases and tissue inhibitors of metalloproteinases in periodontitis-affected human gingival tissue. Arch Oral Biol. 1996;41:253-62.

9- Kubota T, Itagaki M, Hoshino C, Nagata M, Morozumi T, Kobayashi T, et al. Altered gene expression levels of matrix metalloproteinases and their inhibitors in periodontitis-affected gingival tissue. J Periodontol. 2008;79:166-73.

10- Séguier S, Gogly B, Bodineau A, Godeau G, Brousse N. Is collagen breakdown during periodontitis linked to inflammatory cells and expression of matrix metalloproteinases and tissue inhibitors of metalloproteinases in human gingival tissue? J Periodontol. 2001;72:1398-406.

11- Steinberg D, Friedman M, Soskolne A, Sela MN. A new degradable controlled release device for treatment of periodontal disease: in vitro release study. J Periodontol. 1990;61:393-8.

12- Ioannou I, Dimitriadis N, Papadimitriou K, Vouros I, Sakellari D, Konstantinidis A. The effect of locally delivered doxycycline in the treatment of chronic periodontitis. A clinical and microbiological cohort study. J Oral Maxillofac Res. 2011:1;1:e1.

13- Pascale D, Gordon J, Lamster I, Mann P, Seiger M, Arndt W. Concentration of doxycycline in human gingival fluid. J Clin Periodontol. 1986;13:841-4. 
14- Lee HM, Golub LM, Chan D, Leung M, Schroeder K, Wolff $\mathrm{M}$, et al. Alpha 1-Proteinase inhibitor in gingival crevicular fluid of humans with adult periodontitis: serpinolytic inhibition by doxycycline. J Periodontal Res. 1997;32:9-19.

15- Stevanović M, Maksin T, Petković J, Filipic M, Uskoković D. An innovative, quick and convenient labeling method for the investigation of pharmacological behavior and the metabolism of poly (DL-lactide-co-glycolide) nanospheres. Nanotechnology. 2009:19;20:335102.

16- Mundargi RC, Babu VR, Rangaswamy V, Patel P, Aminabhavi TM. Nano/micro technologies for delivering macromolecular therapeutics using poly (D,L-lactideco-glycolide) and its derivatives. J Control Release. 2008;125:193-20.

17- Vandana SC, Khandige MB. The evaluation of doxycycline controlled release gel versus doxycycline controlled release implant in the management of periodontitis. J Indian Soc Periodontol. 2012; 16: 200-206.

18- Sillness, P, Loe, J. Periodontal diseases (II): Correlation between oral hygiene and periodontal conditions. Acta Odonto Scand 1964;22:121.

19- Loe, JB, Silness, P. Periodontal diseases in pregnancy (I): Prevalence and severity. Acta Odonto Scand 1963;21:522.

20- Ramfjord SP. The periodontal index. J Periodontol 1967;38:602.

21- Ladlow JF, Hoffmann WE, Breur GJ, Richardson DC, Allen MJ. Biological variability in serum and urinary indices of bone formation and resorption in dogs. Calscif Tissue Int 2002;70:186-193.

22- Wilson AN, Schmid MJ, Marx DB, Reinhardt RA. Bone turnover markers in serum and periodontal microenvironments. J Periodontal Res 2003;38:355-361.

23- Page RC, Offenbacher S, Schroeder HE, Seymour GJ, Kornman KS. Advances in the pathogenesis of periodontitis: summary of developments, clinical implications and future directions. Periodontol 2000 1997;14:216-48.

24- Machion L, Andia DC, Saito D, Klein MI, Gonçalves RB, Casati MZ, et al. Microbiological changes with the use of locally delivered doxycycline in the periodontal treatment of smokers. J Periodontol 2004;75:1600-1604.

25- Javali MA, Vandana KL. A comparative evaluation of atrigel delivery system (10\% doxycycline hyclate) Atridox with scaling and root planing and combination therapy in treatment of periodontitis: A clinical study J Indian Soc Periodontol. 2012;16:43-8.

26- Ahamed S, Jalaluddin M, Khalid I, Moon N, Shaf TK, Ali FM. The use of controlled release locally delivered $10 \%$ doxycycline hyclate gel as an adjunct to scaling and root planing in the treatment of chronic periodontitis: clinical and microbiological results. J Contemp Dent Pract. 2013;14:1080-6.

27- Tsalikis L, Sakellari D, Dagalis P, Boura P, Konstantinidis A.. Effects of doxycycline on clinical, microbiological and immunological parameters in well-controlled diabetes type- 2 patients with periodontal disease: a randomized, controlled clinical trial. J Clin Periodontol. 2014; 41:972-80.

28- Esmaeili F, Hosseini-Nasr M, Rad-Malekshahi M, Samadi N, Atyabi F, Dinarvand R. Preparation and antibacterial activity evaluation of rifampicin-loaded poly lactide-coglycolide nanoparticles. Nanomedicine. 2007;3:161-7.

29- Moura LA, Ribeiro FV, Aiello TB, Duek EA, Sallum EA, Nociti Junior FH, et al. Characterization of the release profile of doxycycline by PLGA microspheres adjunct to non-surgical periodontal therapy. J Biomater Sci Polym Ed. 2015;26:573-84.

30- Cortellini P, Tonetti MS. Focus on intrabony defects: guided tissue regeneration. Periodontol. 2000;22:104-32.

31- Hujoel PP, Moulton LH. Evaluation of test statistics in splitmouth clinical trials. J Periodontal Res. 1988; 23:378-80.

32- Needleman I, Tucker R, Giedrys-Leeper E, Worthington H. Guided tissue regeneration for periodontal intrabony defects - A Cochrane Systematic Review. Periodontol 2000. 2005;37:106-23.

33- Wenzel A, Warrer K, Karring T. Digital subtraction radiography in assessing bone changes in periodontal defects following guided tissue regeneration. J Clin Periodontol. 1992;19:208-13.

34- Sorsa T, Uitto VJ, Suomalainen K, Vauhkonen M, Lindy S. Comparison of interstitial collagenase from human gingival, sulcular fluid and polymorphonuclear leukocyte. J Periodontal Res 1988;23:386-393.

35- Preshaw PM, Hefti AF, Jepsen S, Etienne D, Walker C, Bradshaw MH. Subantimicrobial dose doxycycline as adjunctive treatment for periodontitis. J Clin Periodontol. 2004; 31:697-707.

36- Garrett S, Johnson L, Drisko CH, Adams DF, Bandt C, Beiswanger B, et al. Two multi-center studies evaluating 
locally delivered doxycycline hyclate, placebo control, oral hygiene, and scaling and root planing in the treatment of periodontitis. J Periodontol. 1999;70:490-50.

37- Polson AM, Garrett S, Stoller NH, Bandt CL, Hanes PJ, Killoy WJ, et al. Multi-center comparative evaluation of subgingivally delivered sanguinarine and doxycycline in the treatment of periodontitis. II. Clinical results. J Periodontol. 1997;68:119-26.

38- Wennström JL, Newman HN, MacNeill SR, Killoy WJ, Griffiths GS, Gillam DG, et al. Utilisation of locally delivered doxycycline in non-surgical treatment of chronic periodontitis. A comparative multi-centre trial of 2 treatment approaches. J Clin Periodontol. 2001;28:753-61.

39- Choi DH, Moon IS, Choi BK, Paik JW, Kim YS, Choi $\mathrm{SH}$, et al. Effects of sub-antimicrobial dose of doxycycline therapy on crevicular fluid MMP-8 and gingival tissue MMP-9. TIMP-1 and IL-6 levels in chronic periodontitis. J Periodontal Res. 2004;39:20-6.
40- Bakó J, Szepesi M, Márton I, Borbély J, Hegedûs C. Synthesis of nanoparticles for dental drug delivery systems. Fogorv Sz. 2007;100:109-13.

41- Kabanov AV, Gendelman HE. Nanomedicine in the diagnosis and therapy of neurodegenerative disorders. Prog Polym Sci. 2007;32:1054-1082.

42- Tüter G, Kurtiş B, Serdar M. Effects of phase I periodontal treatment on gingival crevicular fluid levels of matrix metalloproteinase- 1 and tissue inhibitor of metalloproteinase-1. J Periodontol. 2002;73:487-93.

43- Popat R, Bhavsar NV, Popat PR. Gingival crevicular fluid levels of Matrix Metalloproteinase-1 (MMP-1) and Tissue Inhibitor of Metalloproteinase-1 (TIMP-1) in periodontal health and disease. Singapore Dent J. 2014;35:59-64.

44- Bildt MM, Bloemen M, Kuijpers-Jagtman AM, Von den Hoff JW. Matrix metalloproteinases and tissue inhibitors of metalloproteinases in gingival crevicular fluid during orthodontic tooth movement. Eur J Orthod. 2009;31:529-35. 